\title{
A Construção do Direito Internacional como Disciplina Jurídica no Japão sob a Influência Eurocêntrica: da Era Edo (1603-1868) à Era Showa (1926-1989)
}

\author{
The Construction of International Law as Legal Discipline in Japan under the \\ Eurocentric Influence: from Edo Period (1603-1868) to Showa Period (1926-1989)
}

\author{
Érika Louise Bastos Calazans \\ Universidade Federal de Santa Catarina - Florianópolis, SC, Brasil
}

\begin{abstract}
Resumo: O presente ensaio tem por escopo apresentar um estudo panorâmico acerca dos matizes teóricos que construíram a ciência do direito internacional ao longo do processo de formação do Estado do Japão. O recorte temporal da pesquisa vai de Edo a Showa e divide-se em duas partes. Na primeira, esboça em linhas gerais a introdução da disciplina no país, ainda no período feudal (Era Edo), com seu rápido crescimento no período seguinte. Na Era Meiji, o Japão sustentou ter alcançado o status de "nação civilizada" alegando ter realizado o estrito cumprimento do direito internacional em suas relações estrangeiras, tendo incorporado fortemente a cultura europeia no seu contexto jurídico-político. Na segunda parte, busca apresentar e discutir a consolidação do direito internacional como disciplina jurídica nas Eras Taisho e Showa. Por meio dos métodos dedutivo e qualitativo, concluiu-se que a principal influência no direito internacional no Japão foi a do positivismo jurídico europeu, seguido da introdução do método histórico de análise do direito.
\end{abstract}

Palavras-chaves: Direito Internacional. História do Direito. Japão.
Abstract: The present essay aims at presenting a panoramic study on the theoretical nuances that have built the science of international law throughout the process of formation of the State of Japan. The temporal cutting of the research goes from Edo to Showa and is divided into two parts. In the first, it outlines the introduction of international law in the country, still in the feudal period (Edo), with its rapid growth in the following period. In Meiji Period, Japan maintained that it had achieved the status of "civilized nation" on the grounds that it had carried out strict compliance with international law in its foreign relations, strongly incorporating European culture in its legal-political context. In the second part, it searches to present and discuss the consolidation of international law as legal discipline in Taisho and Showa Periods. Through the deductive and qualitative research methods it was concluded that the main influence on the international law in Japan was the European legal positivism, followed by the introduction of the historical method of legal analysis.

Keywords: International Law. Law History. Japan

Recebido em: 08/03/2017

Revisado em: 12/11/2017

Aprovado em: 14/11/2017 


\section{Introdução}

O presente trabalho busca apresentar uma visão panorâmica dos matizes teóricos que construíram a ciência do direito internacional ao longo do processo de formação do Estado do Japão. O recorte temporal da pesquisa vai da Era Edo (1603-1868) até a Era Showa (1926-1989), dividindo-se em duas partes. Na primeira, tem como cerne a introdução da disciplina no país, ainda no período feudal (Era Edo), sob a influência inicial do direito natural; e vai até o final da Era Meiji, quando o positivismo jurídico como método de estudo do direito internacional ganha proeminência. Na segunda, busca apresentar e discutir a consolidação do direito internacional como disciplina jurídica na Era Taisho (Primeira Guerra Mundial), até meados da Era Showa (Períodos Pré e Pós-Segunda Guerra Mundial), com o refinamento do pensamento dos juristas japoneses, que passaram a adotar um posicionamento mais crítico e menos passivo em relação à cultura jurídica europeia. O objetivo é refletir sobre as mudanças no pensamento dos juristas japoneses, cuja principal influência foi a do positivismo jurídico.

A concepção ocidental ${ }^{1}$ do direito internacional no Japão foi introduzida no meio do século XIX, com a chegada dos navios negros (kurofune $)^{2}$ do Comodoro norte-americano Matthew Perry. Os japoneses que ainda estavam em plena era feudal e forte política nacional de isolamento não tinham o menor conhecimento do direito das gentes ${ }^{3}$. $\mathrm{O}$ estudo

\footnotetext{
${ }^{1}$ Segundo Urs Matthias Zachmann dizer que o direito internacional chegou ao Japão somente com o Comodoro Perry em 1853 é uma afirmação eurocêntrica, uma vez que a noção de direito internacional pode ser entendida em sentido lato para acomodar concepções não ocidentais. Além disso, também defende que a ideia de isolamento do Japão na Era Edo é relativa, visto que mantinha relações comerciais com nações da Ásia oriental, mesmo que de forma limitada (ZACHMANN, 2014).

${ }^{2}$ Kurofune ou navios negros, foi o termo dado pelos japoneses da Era Edo para se referirem aos navios do Comodoro Matthew Perry. A expedição era composta de quatro navios: Mississippi, Plymouth, Saratoga e Susquehanna (PALACIOS, 2008).

${ }^{3}$ Zachmann também entende que o Japão foi capaz de se adaptar mais rapidamente que outros países asiáticos as noções ocidentais pois já possuíam a noção de estado soberano e igualdade soberana, elementos básicos do direito internacional que existiam desde o início da era moderna. Assim afirma: "[...] Japanese international lawyers argued that the
} 
da matéria começou no Japão por motivos práticos e de sobrevivência e, com a abertura forçada do país para o ocidente, se viram obrigados a buscar compreender e aplicar o direito internacional nas suas novas relações diplomáticas.

Durante o final da Era Edo e durante toda a Era Meiji (1868-1912) o estudo da ciência do direito internacional se devotou a descrever o mais precisamente possível e com o maior número de detalhes os fatos, casos e normas existentes no mundo ocidental. Rapidamente o governo japonês percebeu duas importantes questões: primeiro, dominar o conhecimento da disciplina seria essencial para revisar os diversos tratados internacionais que foi levado a fazer no processo de abertura para o ocidente. Segundo, para que o Japão pudesse concretizar seu desejo de ser reconhecido como "nação civilizada" pelo ocidente, precisava provar seu conhecimento e capacidade de seguir estritamente as normas de direito internacional. Somente após as guerras Sino-Japonesa (1894-1895) e Russo-Japonesa (1904-1905), e seu fiel cumprimento do direito internacional na condução das hostilidades, que o Japão conseguiu ser reconhecido.

A partir da Era Taisho (1912-1926), o estudo da disciplina passou a realizar uma sistematização lógica de tratados e conceitos essenciais. O conhecimento e compreensão dos japoneses evoluíram sensivelmente e foi na pessoa de Sakutaro Tachi (1874-1943) que se concretizaram. Tachi discutiu casos compilados por seus predecessores da Era Meiji, entretanto, diferentemente dos pensadores anteriores, seus trabalhos demonstraram certa originalidade. Ele foi além da mera descrição para uma análise e interpretação lógica da lei, sob forte influência de L. Oppenheim e W. Hall.

Do início da Era Showa ao período Pós-Segunda Guerra Mundial (1939-1945) outras importantes contribuições foram realizadas por três internacionalistas: Kisaburo Yokota (1896-1993), Ryoichi Taoka (18981985) e Shigejiro Tabata (1911-2001). Yokota, discípulo de Tachi, foi responsável por influenciar profundamente os círculos acadêmicos de sua

notions of state sovereignty and equality as basic elements of international law existed in Japan even during the early modern period, which of course served as an explanation of why Japan adapted to the western order so much more quickly than, for example, China." (ZACHMANN, 2014, p. 229) 
época. Ele introduziu a teoria pura do direito de Kelsen, como método de estudo da ciência do direito internacional e defendeu a primazia do direito internacional sobre o direito interno.

Já Taoka, introduziu o método histórico de análise do direito internacional e Tabata, também filiado a esta escola, defendeu a importância de dar aos fenômenos históricos seu devido reconhecimento e perceber sua influência na criação da norma de direito internacional. Foi nesse período que o direito internacional se consolidou como disciplina no Japão. Tendo sido marcado pelo progresso da teoria geral do direito internacional com forte influência positivista, mas ao mesmo tempo com uma abordagem orientada pela paz. Por meio dos métodos dedutivo e qualitativo, concluiu-se que o estudo da ciência do direito internacional no Japão passou por diversas transformações desde a Era Edo: foi do total desconhecimento para a praticidade; da passividade descritiva para a análise lógica jurídica, permanecendo profundamente eurocêntrico.

\section{A Introdução do Direito Internacional no Final da Era Edo (1603-1868) e Início da Era Meiji (1868-1912)}

Nesta seção busca-se apresentar a introdução do Direito Internacional na Era Edo e o desenvolvimento da disciplina até início da restauração Meiji, quando a disciplina ganhou seus primeiros contornos modernos. $\mathrm{Na}$ Era Edo os samurais não sabiam do que se tratava o direito internacional, muito embora, o ocidente já estivesse em pleno período de formação da sociedade internacional. Na Era Meiji o Japão vivenciou um rápido crescimento e aprofundamento do estudo de tratados e costumes internacionais, o que lhe permitiu articular melhores relações externas com outros estados soberanos e melhorar sua posição na sociedade internacional.

\subsection{O Primeiro Contato com o Direito Internacional no Crepúsculo da Era Edo}

Enquanto no início do século XVII a Europa começava a formar a sociedade internacional, composta de recém-nascidos estados soberanos, 
o Japão caminhava na direção oposta ${ }^{4}$. O terceiro xogum do Japão, Tokugawa Iemitsu, introduziu durante o Período Edo, a "política de exclusão"5 também conhecida como sakoku, que permaneceu efetiva por dois sécu-

${ }^{4}$ O Japão estava em plena era feudal e o conceito de estado ainda era fluido. O processo de unificação do país foi permeado por conflitos militares e teve como protagonistas, sucessivamente, três senhores feudais (daimyos) Oda Nobunaga, Toyotomi Hideyoshi e Tokugawa Ieyasu. No entanto, foi Tokugawa Ieyasu que efetivamente unificou o Japão, consolidando seu poder ao ganhar a batalha de Sekigahara contra os herdeiros de Hideyoshi em 1600 (PALACIOS, 2008).

${ }^{5} \mathrm{O}$ primeiro contato do Japão com os Europeus data do século XVI e foi por meio dos portugueses, seguidos pelos espanhóis e os holandeses. Muitos daimyos, como Oda Nobunaga, viam a rentabilidade do intercâmbio comercial com os europeus e, por isso, inicialmente permitiram a evangelização dos japoneses pelos jesuítas que se estabeleceram em seu território. Tokugawa Ieyasu (1542-1616) permitiu o comércio com estrangeiros mas proibiu a propagação de ideias cristãs no Japão ao perceber que os portugueses e espanhóis estavam mais interessados em evangelizar as elites feudais do que estabelecer relações comerciais. Em 1639, Tokugawa Iemitsu (1604-1651), o terceiro xogum, decretou que nenhum japonês poderia deixar o país sob pena de morte. Além disso, Iemitsu decretou o fechamento completo do Japão para o mundo exterior ao proibir a entrada no país de todos os navios estrangeiros, exceto aqueles provenientes dos quatro portões (entradas) de Tokugawa (Entrada de Matsumae, Entrada de Tsushima, Entrada de Nagasaki e Entrada de Satsu). Esta foi a chamada "Política de Exclusão" ou sakoku (OTSUKA, 1969). Segundo Palacios, os motivos para essa exclusão dos jesuítas e franciscanos era: "En abril de 1612, Tokugawa ha mandado cerrar las iglesias cristianas y despojar a los misioneros extranjeros de sus residencias y propiedades. Los evangelizadores comenzaron a ser vistos como un peligro para el Estado japonés, se consideró que se estaban convirtiendo en posible factor desestabilizador. Este abrupto cambio de política respecto a la religión extranjera seguro tuvo varios motivos (...): la intolerancia misma de los católicos y las posibles intrigas del clero budista; a lo anterior se pueden sumar las intrigas propias entre las distintas órdenes religiosas, las conductas unilaterales que en ocasiones asumían españoles y portugueses, la cercanía con Ieyasu del protestante William Adams, quien representaba los intereses holandeses - a quienes no les importaba mucho el asunto de la religión y sí por completo el del comercio. Dos años más tarde Ieyasu promulgó un edicto donde se determinaba la expulsión definitiva de los misioneros extranjeros, mientras que los cristianos locales se vieron obligados a renunciar a la fe cristiana, bajo pena de ser torturados y ejecutados. Podríamos delimitar lo anterior - bajo el mandato de Ieyasu - como una persecución religiosa, pero que en los siguientes años se convertirá en base de una inmediata persecución anti-extranjera que llevó al aislamiento definitivo de Japón durante doscientos años aproximadamente" (PALACIOS, 2008, p. 50). 
los e meio, consolidando o isolamento político do Japão em relação ao ocidente $^{6}$.

Somente no meio do século XIX o Japão foi ter conhecimento da existência do direito internacional. Em 1853, os Estados Unidos despacharam o Comodoro Matthew Perry para estabelecer relações comerciais com o Japão. Perry chegou em Uraga com a missão de entregar uma car$\operatorname{ta}^{7}$ do Presidente Millard Fillmore endereçada ao "Imperador" do Japão, com o pedido de abertura do país (OTSUKA, 1969). Foi nessa ocasião que o Governo feudal de Edo estabeleceu relações diplomáticas entre os dois países e o processo de abertura do Japão teve início.

O resultado deste primeiro contato foi o Tratado de Paz e Amizade entre Estados Unidos e Japão de 1854, também conhecido como Tratado de Kanagawa (Kanagawa Jōyaku) (TORIMOTO, 2017) ${ }^{8}$. O artigo IX do Tratado de Kanagawa previa a cláusula da nação mais favorecida e permitia aos Estados Unidos o envio de cônsules e agentes diplomáticos para residir em Shimoda. Depois de concluir tal tratado com os Estados Unidos, o Japão logo fez o mesmo com a Inglaterra, em outubro de 1854,

\footnotetext{
${ }^{6}$ Segundo Lam, a política de exclusão de Tokugawa não era exclusiva, mas seletiva, pois ainda mantinha contato com o exterior através de quatro entradas: entrada de Matsumae, para realizar comércio com os Ainu em Ezo; entrada de Tsushima, para transações comerciais com a Coreia; entrada de Nagasaki, para negócios com a China e a Holanda, e a entrada de Satsu, para manter comércio com o Reio de Ryukyu (LAM, 2013, p. 5).

7 O Presidente Millard Fillmore na carta endereçada ao Imperador demonstrou cordialidade e deixou claro que não tinha interesse em interferir em questões religiosas ou na política interna do Japão, tendo tão somente o interesse de estabelecer relações comerciais: "I have directed Commodore Perry to assure your imperial majesty that I entertain the kindest feelings towards your majesty's person and government, and that I have no other object in sending him to Japan but to propose to your imperial majesty that the United States and Japan should live in friendship and have commercial intercourse with each other. The Constitution and laws of the United States forbid all interference with the religious or political concerns of other nations. I have particularly charged Commodore Perry to abstain from every act which could possibly disturb the tranquility of your imperial majesty's dominions." (PINKERT; POTTER, 2004, p. 140).

${ }^{8}$ O Tratado de Kanagawa foi usado pelos Estados Unidos da América para acabar com o sakoku estabelecido pelo Shogunato Tokugawa, forçando o Japão a abrir os portos de Shimoda e Hakodate para os americanos (TORIMOTO, 2017).
} 
com a Rússia, em fevereiro de 1855 e com a Holanda, em novembro de 1855 (OTSUKA, 1969).

Em janeiro de 1858, os Estados Unidos negociaram um segundo tratado com o Japão: o Tratado de Comércio e Navegação, também conhecido como Tratado de Harris (Nichibei Shūkō Tsūshō Jôyaku) ${ }^{9}$. Townsend Harris foi o grande articulador do tratado e também o primeiro cônsul americano no Japão (KURIYAMA, 1957). No mesmo ano, o Japão se viu obrigado a negociar tratados da mesma natureza com a Rússia, Inglaterra, França e Holanda. Dessa forma, a abertura do Japão para o ocidente estava oficialmente completa.

O Japão buscava se inserir na sociedade internacional, e em razão das pressões sofridas acabou por firmar tratados internacionais, que em sua maioria, eram desiguais. O ocidente, em busca de dominação política e econômica, se aproveitou da inexperiência e ignorância inicial japonesa, para incluir cláusulas abusivas nos tratados firmados, tais como a extraterritorialidade, a cláusula da nação mais favorecida e as restrições à autonomia tarifária (ONUMA, 1986).

Durante as relações estabelecidas entre Estados Unidos e Japão, constante referência ao direito internacional foi feita. No entanto, os oficiais do Governo de Edo tinham pouco ou quase nenhum conhecimento da ciência do direito internacional. O parâmetro utilizado por eles, para buscar entender este novo conhecimento, era o direito natural de bases confucionistas. $^{10}$

\footnotetext{
${ }^{9} \mathrm{O}$ Tratado de Kanagawa não possuía a cláusula de livre comércio entre Japão e Estados Unidos e foi o Tratado de Harris que trouxe tal inovação. Este tratado se tornou o modelo para os Tratados Ansei (assim conhecidos pela sua desigualdade), com a Rússia, Inglaterra, França e Holanda, no mesmo ano, que deixavam o Japão em grande desvantagem.

${ }^{10}$ A filosofia de Confúcio, proveniente da China, baseava-se, principalmente na ideia de ética na condução da vida política. Por exemplo, honradez entre governantes e súditos; respeito à hierarquia entre pais e filhos; respeito aos mais velhos e fidelidade entre amigos. Durante o sakoku, o estudo do confucionismo se tornou mais refinado e sofisticado no Japão. Uma nova escola do pensamento surgiu à época chamada Kokugaku, que criticava severamente toda a filosofia confucionista. A crítica se baseava no fato de acreditarem ser o confucionismo extremamente normativista e opressor dos sentimentos e emoções humanas, além de ser uma forma de submissão à China.
} 
O xogunato de Tokugawa ordenou que oficiais do governo, como Shusuke Nishi (mais tarde Amane Nishi) e Shindo Tsuda fossem estudar e entender a ciência do direito internacional na Holanda. Eles foram orientados pelo Professor Simon Vissering (1818-1888) da Universidade de Leyden, cujas aulas foram traduzidas para o japonês em 1867 (ITO, 1969; OTSUKA, 1969).

Nishi e Tsuda publicaram livros ${ }^{11}$ no Japão com base nos estudos realizados na Holanda. As lições aprendidas por Nishi foram repassadas para estudantes da matéria. Em 1868, as primeiras aulas de direito internacional, baseadas na doutrina do direito natural, aconteceram no país (ITO, 1969). No entanto, a forma em que os japoneses entendiam o direito natural era diferente da compreensão cristã europeia. E, por isso, o pensamento sobre o direito natural de Vissering era entendido com base na ideia de justiça do universo e nos pensamentos de Confúcio.

Apesar das importantes contribuições de Nishi para popularização da ciência do direito internacional, no início do Governo Meiji, foi o livro "Elementos de Direito Internacional", que aprofundou o estudo da disciplina (WHEATON, 1836). Esse livro foi escrito pelo jurista norte-americano Henry Wheaton (1785-1848), traduzido por W. A. P. Martin para o chinês em 1864, sob o título Wanguo Gongfa ${ }^{12}$ e reimpresso no Japão no ano seguinte com o título em japonês Bankoku Kōhō.

A versão chinesa se tratava de um resumo da obra e se mostrou de difícil entendimento para os japoneses por dois motivos. Primeiro, continha diversos erros de tradução que causavam incorreta interpretação de alguns apontamentos teóricos apresentados por Wheaton (OTSUKA, 1969; LAM, 2013). Por exemplo, Wheaton afirmava que a lei da natureza (law of nature) que era utilizada para resolver disputas entre estados, deu origem a um novo ramo do direito, o jus gentium. $\mathrm{O}$ autor, afirmava ainda que esse mesmo direito natural também poderia ser entendido como normas de justiça (rules of justice) que governava a conduta do ho-

\footnotetext{
${ }^{11}$ O livro de Tsuda Shindo foi intitulado "Um tratado sobre o Direito Público do Ocidente" (Taisei Kokuho ron) e o livro de Shusuke Nishi foi uma introdução ao direito internacional e intitulava-se Koho teroku.

${ }^{12} \mathrm{O}$ sentido literal de Wanguo Gongfa é direito público de dez mil estados (LAM, 2013, p. 5).
} 
mem e que, portanto, poderiam ser chamadas de leis de Deus ou lei divina (WHEATON, 1836; LAM, 2013). No entanto, em razão da aparente ambiguidade das afirmações de Wheaton (1836), Martin traduziu o texto como se a lei emanasse de Deus e tratou o direito natural e o jus gentium como se fossem sinônimos (LAM, 2013, p. 11). O segundo foi o fato de as elites japonesas em geral serem intelectualmente despreparadas para os novos termos jurídicos ocidentais, já que conheciam pouco ou quase nada da história europeia e ocidental. Como consequência, o livro foi um marco para a introdução dos valores ocidentais no Japão (LAM, 2013, p. 12).

O livro de Wheaton (1836) possuía bases metodológicas no positivismo, sendo este o grande mérito do seu trabalho, que nos anos seguintes, com as novas traduções diretamente do inglês para o japonês, começou a ser melhor compreendido pelo Japão. Wheaton (1836) reconhecia a aplicação do princípio de justiça internacional como fonte da ciência do direito internacional e das relações internacionais, bem como reconhecia a existência do direito natural como base do positivismo ${ }^{13}$. No entanto,

${ }^{13} \mathrm{Na}$ edição de seu livro de 1836, que chegou ao Japão, posteriormente traduzida do inglês para o japonês, Wheaton se inspirou claramente em Vattel, repetindo sua taxonomia da ciência do direito internacional. O autor afirmava: "The law of nations, or international law, as understood among civilized, Christian nations, may be defined as consisting of those rules of conduct which reason deduces, as consonant to justice, from the nature of the society existing among independent nations; with such definition and modifications as may be established by general consent" (WHEATON, 1836, p. 46). Ainda segundo Wheaton, o direito internacional pode ser dividido em dois ramos: "I. What is termed the Natural Law of Nations, consisting of the rules of justice applicable to the conduct of those independent societies of men called states. II. The positive law of nations, which is again subdivided into three branches: 1 . The Voluntary Law of Nations, derived from the presumed consent of nations arising out of their general usage and consent. 2 . The Conventional Law of Nations, derived from the express consent of nations, as evidenced in treaties and other international compacts. 3. The Customary Law of Nations, derived from the tacit consent of particular nations establishing a peculiar usage between themselves" (WHEATON, 1836, p. 47-48). No entanto, o pensamento de Wheaton evoluiu e na edição de 1866 apresentou uma crítica a Vattel e Wolf: "Vattel concludes that these three species of international law, the voluntary, the conventional, and the customary, compose together the positive law of nations. They proceed from the will of nations; or (in the words of Wolf) 'the voluntary, from their presumed consent; the conventional, from their express consent; and the customary, from their tacit consent.' It is almost superfluous to point out the confusion in this enumeration of the different species of international law, which 
seu trabalho não enfatizava o direito natural, mas sim o direito positivo, tendo sido diretamente influenciado por F. K. von Savigny (1779-1861), J. L. Klüber (1762-1836) e A. G. Heffter (1796-1880) (ITO, 1969).

$\mathrm{O}$ direito internacional como disciplina jurídica no Japão sofreu influências do direito natural através das teorias apreendidas por Nishi, quando foi instruído por Vissering, mas acima de tudo, das lições positivistas de Wheaton. O positivismo era aceito sem questionamento e sem nenhuma preocupação de caráter metodológico, pois naquele momento os japoneses, em busca de compreensão, passaram a absorver de forma passiva as concepções ocidentais da ciência do direito internacional (MATSUI, 2002).

\subsection{O Estudo da Ciência do Direito Internacional na Era Meiji}

Em 1868, Tokugawa Yoshinobu, o décimo quinto e último xogum do Japão, passou o poder administrativo para a corte imperial. O governo de Meiji, ${ }^{14}$ que substituiu o governo de Edo, deu fim ao Japão feudal e iniciou a instauração do Japão moderno com influência direta estrangeira.

O novo governo passou então à assinatura de diversos tratados de amizade e comércio: primeiro com a Suécia-Noruega e a Espanha em 1868, em seguida com a Confederação da Alemanha do Norte e a Áustria-Hungria em 1869 (OTSUKA, 1969). Infelizmente, a maioria destes tratados foram firmados com a previsão de cláusulas desvantajosas para o Japão, como já havia acontecido durante a Era Edo.

Assim que tomou o poder, o governo Meiji iniciou diversas reformas no Japão, introduzindo valores ocidentais ao ordenamento jurídico,

might easily have been avoided by reserving the expression, "voluntary law of nations', to designate the genus, including all the rules introduced by positive consent, for the regulation of international conduct, and divided into the two species of conventional law and customary law, the former being introduced by treaty, and the latter by usage; the former by express consent, and the latter by tacit consent between nations."'(WHEATON, 1866, p. 16).

${ }^{14} \mathrm{O}$ contexto político no Japão mudou drasticamente com a Restauração Meiji, assim chamada em razão da restituição dos poderes do imperador, que criou oligarquias patriarcais e desse momento em diante perseguiu drástica modernização do país. 
que passou a ser baseado no princípio universal de justiça (KURIYAMA, 1957). A grande contribuição do governo Meiji foi a tradução e publicação de diversos tratados internacionais para o japonês, facilitando o acesso a informação para a academia jurídica que se formava. Em pouco tempo, os líderes políticos japoneses começaram a perceber o significado e as consequências das exigências dos diversos tratados internacionais desiguais que assinaram desde 1854 (ONUMA, 1986).

A primeira missão de caráter diplomático do Japão foi a revisão destes diversos tratados desequilibrados. Para obter tal objetivo, o estudo aprofundado da ciência do direito internacional tornou-se essencial. A partir daí o direito internacional, como disciplina jurídica, passou a ser estudado com grande entusiasmo. O governo Meiji percebeu que era essencial dominar esse conhecimento e a arte da negociação de revisões. Além disso, observou também que para conseguir qualquer revisão, precisava convencer o Ocidente a reconhecer o Japão como "nação civilizada" 15 . Para tanto, precisava demonstrar seu total comprometimento com a aplicação do direito internacional. Tal reconhecimento foi essencial para conseguir rever e abolir as cláusulas abusivas (ZACHMANN, 2014).

Segundo Onuma (1986), o estudo da ciência do direito internacional na Era Meiji foi marcado por quatro características: prático, estatalista, passivo e eurocêntrico. Prático, pois buscava se ater ao que era direta-

${ }^{15} \mathrm{O}$ principal objetivo da política estrangeira do governo Meiji era renegociar os tratados inicialmente concluídos com potências ocidentais entre 1858 e 1869 e alcançar uma posição de igualdade com a Europa. O Japão, logo com a conclusão do último tratado, tentou fazer uma renegociação. No entanto, as potências ocidentais, em especial o Reino Unido, argumentaram que o Japão ainda não havia alcançado os critérios de civilidade necessários para tal renegociação. Isso gerou uma completa mudança nos padrões da sociedade japonesa e influenciou profundamente o processo drástico de modernização do país. Até então, a China havia sido o padrão cultural no início do Japão moderno, e este ponto de referência foi abandonado para o paradigma da ideia de "civilidade europeia" ou bunmei kaika, que simplesmente significa "europeu”, e por extensão, cultura europeia. Assim, a ideia de "deixar" a Ásia e juntar-se a Europa tornou-se popular, por se tratar de uma questão de poder. Para tanto, o Japão teria que conhecer e demonstrar a aplicação do direito internacional em sua relação com as potências ocidentais, mas também em relação aos seus vizinhos (ZACHMANN, 2014). 
mente útil para os objetivos diplomáticos do governo japonês. Estatalista, pois as principais demandas eram feitas pelo governo e os publicitas acreditavam que seu dever era atender as necessidades do Estado. Passivo, por simplesmente aceitar os conceitos e princípios do direito vindos do estrangeiro. Eurocêntrico, pois, o estudo da disciplina jurídica era todo conduzido com base na ocidentalização da sociedade japonesa, em especial com conceitos jurídicos de países europeus.

Em 1895, a cadeira de direito internacional começou a ser ensinada na Universidade Imperial de Tokyo, em tempo integral, por Tōru Terao (1895-1900), seguido de Sakue Takahashi (1901-1906) e sucedido por Sakutaro Tachi (1907-1943) (MATSUI, 2002). Em 1902, a Associação de Direito Internacional criou a publicação mensal da Revista de Direito Internacional, fundada por Saburo Yamada, para divulgar os resultados e desenvolvimentos no estudo da disciplina que, em 1912, passou a ser chamada de Revista de Direito Internacional e Diplomacia (KURIYAMA, 1957).

Durante este período diversos proeminentes juristas e pesquisadores surgiram e fizeram significativas contribuições para a ciência do direito internacional, como, Nagao Ariga, Sakue Takahashi, Masanosuke Akiyama, Shingo Nakamura, Kazuo Matsubara, Genroku Endo e Tsurutaro Senga (ITO, 1969).

Segundo Fujio Ito (1969), tais estudiosos representavam a nova geração de juristas japoneses especializados na ciência do direito internacional. $\mathrm{O}$ estudo deste ramo do direito passou a enfatizar a discussão positiva, com a correta descrição dos fatos por meio da análise de seus precedentes. No entanto, a maioria destes autores citavam teorias europeias e americanas como fundamento de suas visões, muitas vezes, apenas enumeravam tais teorias, sem efetivamente discutirem seus fundamentos com profundidade (ITO, 1969). Dessa forma, as contribuições foram introdutórias e explanatórias, com o objetivo de elucidar a academia dos conceitos essenciais da ciência do direito internacional. 


\subsection{A Aplicação do Direito Internacional Durante as Guerras Sino-Ja- ponesa (1894-1895) e Russo-Japonesa (1904-1905)}

Na guerra entre China e Japão, o direito internacional foi aplicado amplamente, pela primeira vez, entre duas nações não cristãs. Esse conflito juntamente com a guerra Russo-Japonesa foram responsáveis pelo amplo estudo positivo do direito de guerra no Oriente.

A guerra Sino-Japonesa foi a primeira de caráter internacional do Japão, por isso o governo japonês determinou ampla aplicação do direito internacional. Isso fica claro no Edito Imperial para Soldados e Marinheiros do Japão de 1882:

Comandamos que cada uma e todas as quatro autoridades competentes, em obediência ao nosso desejo e com o objetivo de alcançar tal desejo, conduzir as hostilidades no mar e na terra com todos os meios à sua disposição, consistentemente de acordo com a lei das nações. (Edito Imperial para Soldados e Marinheiros do Japão de 1882 apud TAKAHASHI, 1898, p. 405)

Segundo a doutrina jurídica japonesa, por meio da condução das hostilidades em estrita conformidade com o direito internacional, o Japão pôde comprovar seu "valor", para receber o tão desejado reconhecimento como "nação civilizada" por parte da Europa (ISHIMOTO; HIROBE, 1987). Os próprios juristas europeus reconheceram o distinto sucesso japonês em conseguir seu lugar entre as Grandes Potencias. Assim afirma Oppenheim (1905, p. 33):

Another non-Christian member of the Family of Nations is Japan. Some years ago, one might have doubted whether Japan was a real and full member of that family, but since the end of the nineteenth century no doubt is any longer justified. Through a marvelous effort, Japan has become not only a modern State, but an influential Power. Since her war with China in 1895, she must be considered one of the Great Powers that lead the Family of Nations.

Para alcançar tal reconhecimento, o Japão contou com o apoio de juristas japoneses no processo de instrução e aconselhamento das for- 
ças armadas. Os principais publicistas responsáveis pela "propaganda" favorável ao Japão na Europa foram Nagao Ariga (1860-1921) e Sakue Takahashi (1867-1920).

Nagao Ariga, professor da Academia do Exército Japonês e Sakue Takahashi, professor da Universidade Imperial de Tokyo, foram designados para acompanhar e prestar seus conselhos jurídicos para o exército e para a marinha, respectivamente. Ariga acompanhou e aconselhou de perto o Chefe em Comando do Exército, o Conde Oyama, e Takahashi, o Almirante Ito da Marinha (TAKAHASHI, 1898). Esses juristas orientaram as forças armadas japonesas a seguir o direito de guerra conforme o espírito samurai e o espírito tradicional de irmandade (KURIYAMA, 1957). Durante a guerra Russo-Japonesa mais uma vez o Japão observou estritamente as regras de direito internacional na condução de suas ações. E, novamente, os Professores Nagao Ariga e Sakue Takahashi foram designados a aconselhar o exército e a marinha.

O papel desempenhado por Ariga como conselheiro do exército nestes dois conflitos lhe forneceu a experiência e o conhecimento necessários para escrever duas grandes obras: La guerre Sino-Japonaise au point de vue du droit international (1896) e La guerre Russo-Japonaise au point de vue du droit international (1908). Sakue Takahashi também escreveu dois livros sobre as guerras com base nos casos coletados: Cases on International Law during the Chino-Japanese War (1899) e o International Law applied to the Russo-Japanese War with the Decisions of The Japanese Prize Court (1908). As obras foram propositalmente escritas em inglês e francês para facilitar a disseminação da "boa conduta" japonesa e demonstrar seu comprometimento com o direito internacional.

Takahashi (1898) ao comparar a postura da China e do Japão durante a Guerra Sino-Japonesa deixou clara sua interpretação:

A China não era um dos signatários da Declaração de Paris, e, além disso, ela nunca tinha feito qualquer esforço para entrar em qualquer convenção desse tipo; mas foi o propósito do Japão, não obstante a natureza de seu oponente, dar um exemplo de generosidade através da condução das hostilidades de forma esclarecida e legitimada na lei. (TAKAHASHI, 1898, p. 405) 
Os autores utilizaram como fundamento de validade de seus posicionamentos em defesa do Japão, os diversos casos e materiais que coletaram ao longo dos dois conflitos, com tendências positivistas. Por exemplo, Takahashi explicou de forma detalhada a postura do Japão ao aplicar o direito internacional em casos famosos, como o Caso Kowshing de 1894, o Caso do Gaelic e Sidnei de 1894 e o Caso Yik-sang e Pequim de 1895 (TAKAHASHI, 1898). Os livros ganharam grande notoriedade e foram grandes influenciadores no processo de reconhecimento do Japão como "nação civilizada" pelo ocidente. Outros grandes autores japoneses que escreveram sobre as duas guerras foram Genroku Endo, Jisaku Shinoda e Nichiro Sen'eki. O foco neste período foi a pesquisa e estudo sistematizado desses dois conflitos, com aplicação do direito positivo existente (ONUMA, 2002).

\section{A Ciência do Direito Internacional nos Períodos Pré e Pós Guerras Mundiais: da Era Taisho (1912-1926) à Era Showa (1926-1989)}

Esta seção visa discutir a consolidação da ciência do Direito Internacional no Japão nos períodos Pré e Pós-Guerras Mundias, também conhecidos como Era Taisho e Era Showa no Japão. Durante esses períodos, o positivismo foi o método de estudo mais utilizado pelos doutrinadores da época, no entanto logo no final da Era Taisho e ínicio da Era Showa também passaram a utilizar o método histórico para estudar o direito internacional. Optou-se neste estudo por mencionar apenas alguns dos doutrinadores mais celebrados à época, devido às grandes contribuições acadêmicas realizadas e por transmitirem o pensamento predominante de sua geração.

\subsection{O Positivismo como Método de Estudo da Ciência do Direito Inter- nacional}

Com base no estudo realizado, sustenta-se a seguir que o positivismo jurídico foi o principal método de estudo do direito internacional no Japão durante a Era Taisho e a Era Showa. Os mais proeminentes doutri- 
nadores que adotaram este método de estudo foram Sakutaro Tachi e seu pupilo Kisaburo Yokota. Tachi possuía uma visão mais ortodoxa e conservadora, com a forte influência de W. E. Hall e L. F. L. Oppenheim. Já Yokota era progressista e adotava fielmente as ideias de Hans Kelsen e a teoria pura do direito, sua grande marca foi no período Pós-Segunda Guerra Mundial, quando o país mudou sua estrutura de poder e a forma de se discutir o direito internacional.

\subsubsection{A Contribuição de Sakutaro Tachi nos Períodos Pré e Pós-Pri- meira Guerra Mundial (1914-1918)}

Desde o início da importação da ciência do direito internacional para o Japão, sua principal influência foi a do positivismo. Durante os períodos Pré e Pós-Primeira Guerra Mundial, o positivismo jurídico foi estabelecido como um método consciente para o estudo da ciência do direito internacional, já que antes disso era aceito de forma passiva pelos japoneses. Dentre os doutrinadores representantes deste ponto de vista, os mais proeminentes deste período, foram sem dúvida, Sakutaro Tachi ${ }^{16}$ (1874-1943) e Kisaburo Yokota (1896-1993) (MATSUI, 2002).

A interpretação do direito internacional no Japão era conservadora e buscava justificar seu anseio por expansão dentro dos moldes do imperialismo europeu (SHINOHARA, 1996). Diversos posicionamentos elaborados por Tachi serviram para justificar as ações do Japão na Ásia (TACHI, 1934). Enquanto seus predecessores estavam preocupados em coletar, organizar e reproduzir diversos casos e materiais, Tachi buscou aprofundar a interpretação jurídica da disciplina. A abordagem de Tachi sobre o estudo da ciência do direito internacional representava uma tendência geral da academia japonesa da época: a mudança de uma abordagem ingênua e descritiva para uma abordagem interpretativa e crítica dos fenômenos jurídicos internacionais (ONUMA, 1986; AKASHI, 2013).

As obras primas de Tachi, baseadas no positivismo jurídico, foram dois livros de setecentas páginas cada, que versavam sobre o direi-

\footnotetext{
${ }^{16}$ Sakutaro Tachi foi um grande internacionalista japonês durante a Era Taisho e primeira metade da Era Showa. Lecionou na Universidade Imperial de Tóquio a partir de 1904, e em 1907, assumiu a cadeira de direito internacional, em substituição de Sakue Takahashi.
} 
to da guerra e da paz: o "Direito Internacional na Paz" de 1930 (Heiji Kokusaiho Ron) e o "Direito Internacional na Guerra" de 1931 (Senji Kokusaiho Ron). Tachi $(1930,1931)$ acreditava que a fonte da ciência do direito internacional era a concordância mútua entre os estados que integravam a comunidade internacional, e a existência dessa comunidade se justificava pela interdependência material e espiritual entre as nações, demonstrando sua clara concordância com a ideia de universalismo do direito internacional.

Esses livros podem ser caracterizados como a primeira tentativa de um jurista japonês de estabelecer sua própria ciência do direito internacional e foram considerados como os textos definitivos da matéria no período Pós-Primeira Guerra Mundial (ONUMA, 1986). Os livros, além de terem sido influenciados pelo pensamento de Lassa Francis Lawrence Oppenheim $^{17}$ (1858-1919) e William Edward Hall (1835-1904) $)^{18}$, representavam a visão que prevalecia na academia: o dualismo entre o direito internacional aplicado em tempo de paz; e o direito internacional aplicado na guerra. A guerra era entendida como fenômeno metajurídico e procedimentos específicos eram estudados para aplicação do direito nesta situ-

\footnotetext{
${ }^{17}$ Sakutaro Tachi descreve em seus manuais o sistema do direito internacional de forma quase idêntica a Oppenheim, revelando claramente a influência decisiva desse autor no seu trabalho (1930). Oppenheim sustentava que o direito Internacional era um conjunto de normas costumeiras ou convencionais obrigatórias entre nações civilizadas no curso de suas relações. Ele defendia a ideia de universalismo do direito internacional, no entanto, não havia autoridade superior capaz de impor as normas para os estados soberanos, por isso, o direito internacional era um conjunto de normas acordadas entre Estado. Assim afirmava o autor: Law of Nations or International Law is the name for the body of customary and conventional rules which are considered legally binding by civilized States in their intercourse with each other. Such part of these rules as is binding upon all the civilized States without exception is called universal International Law, in contradistinction to particular International law, which is binding on two or a few States only. [...] The Law of Nations is a law for the intercourse of States with one another, not a law for individuals. As, however, there cannot be a sovereign authority above the single sovereign states, the Law of Nations is a law between, not above, the single States [...]. (OPPENHEIM, 1905, p. 3-4).

${ }^{18}$ Foi Tachi quem fez a tradução do livro Treatise on International Law de Wall em 1899 e muito do seu conhecimento inicial do direito foi em razão dessa tradução (AKASHI, 2013, p. 131).
} 
ação excepcional. AKASHI (2013, p. 132-133) comenta as duas grandes características de Tachi como jurista:

First, his legal argument proceeds based purely on positive legal rules [...] without introducing political considerations into it. Second, he is a pure positivist in international legal studies, in that he relies on nothing other than treaties and customary international law.

Tachi, como positivista de postura ortodoxa, adotava a teoria $R e$ chtsüberzeugung ${ }^{19}$ para interpretar as normas positivas do direito internacional contidas nos tratados e costume internacional. As normas internacionais eram interpretadas por Tachi (1934) conforme as regras imperialistas, com aberta oposição ao Pacto de Kellogg-Briand de 1928, que tornou a guerra ilegal. Dois argumentos sustentavam sua crítica ao Pacto: primeiro, a renúncia a guerra apresentada no texto não significava renúncia total ao uso da força, pois o Pacto proibia a guerra como instrumento da política nacional dos Estados. Dessa forma, o Pacto não proibia a legítima defesa (TACHI, 1934; SHINOHARA, 1996).

Segundo, as notas diplomáticas do Reino Unido de maio de 1928, nas quais o Ministro das Relações Exteriores declarou que em relação as regiões que afetavam os interesses diretos da Britânia, ela manteria sua liberdade de ação. Tachi chamou tal abordagem de "Nova Doutrina Monroe Britânica" (SHINOHARA, 1996). A partir de 1931 passou a justificar as ações do governo Japonês no incidente na Manchúria (1931-1932), alegando se tratar de legítima defesa (TACHI, 1934).

Durante esse período havia uma grande tendência no Japão em se adotar teorias europeias do século XIX e início do século XX. Os juristas japoneses escreviam livros de direito internacional positivo apresentando os princípios e regras de forma organizada e sistemática. Assim, os principais autores europeus que influenciaram o pensamento dos juristas

\footnotetext{
${ }_{19}$ Com base na teoria Rechtsüberzeugung, Tachi entendia que as fontes do direito internacional são responsáveis por dar efeito a cada norma de direito internacional. As fontes do direito internacional justamente são a convicção da comunidade sobre o direito internacional ou a convicção na lei (AKASHI, 2013, p. 133).
} 
japoneses da época foram: J. L. Klüber, A. W. Heffer, F. de Martens, W. E. Hall, Franz von Liszt e L. F. L. Oppenheim.

Na Era Showa, o estudo da ciência do direito internacional no Japão se voltou para os fundamentos da disciplina. Foi a partir daí que o direito internacional passou a ser uma disciplina independente e não uma mera importação de ciência jurídica estrangeira (MATSUI, 2002).

\subsubsection{A Contribuição de Kisaburo Yokota no Período Pós-Segunda Guerra Mundial (1939-1945)}

Um dos juristas mais proeminentes do período Pós-Segunda Guerra Mundial foi Kisaburo Yokota (1896-1993), pupilo de Sakutaro Tachi. Yokota (1930) importou a teoria pura do direito da Escola de Viena para o Japão e sua pesquisa se baseava nesta metodologia. Ele foi responsável por influenciar profundamente os círculos legais japoneses da época. Em seu livro, intitulado "Direito Internacional" (Kokusaiho ron), com dois volumes e publicado em 1933 e 1934, Yokota deixou claro seu ponto de vista positivista.

A abordagem na teoria pura do direito de Yokota, durante as duas guerras mundiais, foi politicamente suprimida em razão de seu posicionamento crítico sobre as ações do Japão (TAKANO, 1962). Yokota (1934) criticava fortemente a alegação do governo japonês sobre seu direito de legítima defesa para justificar o incidente ocorrido na Manchúria (19311932). Considerando o militarismo e o nacionalismo da época e a constante histeria para se fazer guerra contra a China, tal crítica demonstrou grande coragem por parte de Yokota (SHINOHARA, 1996).

O Édito Imperial de Proclamação de Guerra, de 8 de dezembro de 1941, apesar do mero valor simbólico, demonstra a tendência totalitarista do Japão, bem como a falta de menção do dever de cumprir o direito internacional:

Declaramos guerra aos Estados Unidos da América e ao Império Britânico. Os homens e os oficiais de nosso Exército e da Marinha devem fazer o seu melhor em processar a guerra. Nossos servidores públicos de vários departamentos devem desempenhar fielmente e 
diligentemente as suas respectivas funções; toda a nação com uma vontade unida deve se mobilizar com força total para que nada possa fracassar na obtenção de nossos objetivos de Guerra. (ÉDITO IMPERIAL DE PROCLAMAÇÃO DE GUERRA, 1941)

Enquanto nas guerras Sino-Japonesa e Russo-Japonesa o governo Meiji se mostrou preocupado em dar instruções claras e minuciosas ao exército e a marinha, sobre a importância de seguir o direito internacional na condução das hostilidades, o mesmo não aconteceu durante a Segunda Guerra Mundial. Pelo contrário, a preocupação do governo era enfatizar a obediência às ordens do superior hierárquico, sem qualquer questionamento sobre a legalidade dos atos a serem praticados. Tal prática resultou em um grande número de casos de violações de direito internacional. Diversas violações ocorreram também dada a falta de conhecimento comum do direito internacional pelos soldados que compunham a marinha, a aeronáutica e o exército. Dessa forma, os soldados não podiam analisar se suas ações ou os comandos superiores representavam efetiva violação do jus gentium (ONUMA, 1986).

Somente no período pós-guerra o trabalho de Kisaburo Yokota ganhou efetiva proeminência nos círculos acadêmicos japoneses, tendo sido considerado como a "[...] encarnação do internacionalismo do período pós-guerra" (TAKANO, 1962, p.79). Yokota (1960; 1973) consistentemente defendeu o monismo e a primazia do direito internacional sobre o direito interno, como se esperava de um kelseniano (OBATA, 2006). Entre suas contribuições mais importantes, pode-se citar o seu livro intitulado Direito Internacional de 1948 (Kokusaiho ron), baseado na teoria pura do direito de Hans Kelsen e na crença da existência da comunidade internacional, que foi amplamente lido pela academia e "A Teoria fundamental do direito internacional” de 1949 (Kokusaiho no Kiso Riron).

\subsection{A Introdução do Método Histórico no Estudo da Ciência do Direi- to Internacional na Primeira Metade da Era Showa}

Ryoichi Taoka (1898-1985) introduziu o método histórico no Japão antes do fim da Segunda Guerra Mundial. Ele foi professor da Universidade de Kyoto e se encontrava do lado oposto de Yokota no estudo da 
ciência do direito internacional. Taoka defendia o estudo da norma internacional com base no seu histórico e não necessariamente na lógica de sua estrutura (ISHIMOTO; HIROBE, 1987; MATSUI, 2002).

$\mathrm{O}$ autor acreditava que as normas de direito internacional deveriam ser entendidas através de seu histórico social e político, bem como na sua função social, para que então uma delimitação de sua aplicação pudesse ser realizada. Em outras palavras, Taoka (1937) se opunha ao formalismo da teoria pura do direito, que lidava com a lógica normativa, e focava seu estudo no ponto de vista sociológico, utilizando uma metodologia histórica para examinar a norma. Assim, ele buscou observar as normas de direito internacional conforme sua essência histórica e nas características fundamentais da sociedade internacional (TAKANO, 1962). Além disso, Taoka (1946) buscou racionalizar a validade do direito internacional em conformidade com as realidades da sociedade internacional. Este ponto de vista fica claro em sua obra "Linhas gerais do estudo do Direito Internacional", vol.1, (Kokuseihogaku Taiko) de 1946.

Taoka (1946) criticava a perspectiva de Yokota ao estudar a ciência do direito internacional através de uma analogia entre a comunidade internacional e a doméstica. Ele também analisou a relação entre o direito internacional e o direito interno com base no método histórico, e concluiu que não há diferença entre a abordagem dualista e a abordagem da supremacia do direito internacional em termos da sua forma de interpretação do direito positivo (MATSUI, 2002).

Shigejiro Tabata (1911-2001) foi outro internacionalista que também buscou contribuir para a pesquisa da disciplina por meio do método histórico. $\mathrm{O}$ autor procurava a transcendência da forte influência da teoria pura do direito na ciência do direito internacional no país. Ele reconheceu o valor do positivismo como responsável por realizar uma análise lógica da estrutura jurídica internacional. No entanto, defendia o estudo e a análise das teorias da ciência do direito internacional com base na história do pensamento para que pudesse verificar sua aplicação e limites diante de novas situações (TABATA, 1946; TAKANO, 1962; ISHIMOTO; HIROBE, 1987; MATSUI, 2002). Em seu livro A transformação da concepção de igualdade entre Estados de 1946 (Kokka Byodo Kannen no Tenkan), 
Tabata (1946) sugere que a ideia de igualdade entre estados originava de Samuel Puffendolf (1632-1694) e não de Hugo Grotius (1583-1645).

\subsection{A Mudança na Estrutura do Direito Internacional após a Segunda Guerra Mundial e o Direito Internacional Moderno}

O estudo da ciência do direito internacional mudou consideravelmente após a Segunda Guerra Mundial, sendo facilmente perceptível a diferença entre a ciência do direito internacional clássico, que prevaleceu até a Primeira Guerra Mundial, e a ciência do direito internacional moderno, que ganhou proeminência após a Segunda Guerra Mundial (MATSUI, 2002).

Se, por um lado, a ciência do direito internacional era estudada sob o ponto de vista dualista de Tachi (1934), ou seja, o direito internacional dividia-se em direito internacional da paz e direito internacional da guerra, com uma abordagem estatalista; por outro, com o fim da Segunda Guerra Mundial, o direito internacional da guerra perdeu força e outros aspectos da disciplina passaram a ser mais estudados, com a prevalência da abordagem internacionalista e orientada pela paz $^{20}$ (ONUMA, 1990).

${ }^{20}$ A Constituição Japonesa, promulgada em 1946 e que entrou em vigor em 1947, pode ser considerada um marco na mudança de pensamento da comunidade internacional. Esta constituição foi imposta pelas forças aliadas ao governo japonês, que não desejava substituir a Constituição de 1889 da Era Meiji. No entanto, a nova constituição foi aprovada pela maioria esmagadora do povo japonês, sob o sentimento de vergonha, pelos atos praticados no regime imperial (ONUMA, 1990). A Constituição tem como base de sustentação três princípios básicos: a renúncia da guerra, a soberania popular e o respeito aos direitos e garantias fundamentais. $\mathrm{O}$ advento da Constituição marcou o fim do ultramilitarismo no Japão, do desprezo pelos direitos humanos e da onipotência do deus vivo na pessoa do imperador. $\mathrm{O}$ artigo $9^{\circ}$ da Constituição do Japão demonstra claramente o caminho que o povo daquele país deveria seguir no futuro: a defesa da paz e a renúncia do uso da força. O referido artigo dispõe: "Aspirando sinceramente à paz mundial baseada na justiça e ordem, o povo japonês renuncia para sempre o uso da guerra como direito soberano da nação ou a ameaça e uso da força como meio de se resolver disputas internacionais. Com a finalidade de cumprir o objetivo do parágrafo anterior, as forças do exército, marinha e aeronáutica, como qualquer outra força potencial de guerra, jamais será mantida. O direito a beligerância do Estado não será reconhecido" (CONSTITUIÇÃO DO JAPÃO, 1947). Este artigo, um dos mais importantes da Constituição, determina a renúncia da guerra e proíbe a manutenção de forças armadas 
A herança da Segunda Guerra Mundial foi a certeza de que o uso da força deveria ser banido como alternativa legal para a resolução dos conflitos entre os estados soberanos. O sentimento que predominava na comunidade internacional era de que as atrocidades cometidas na Primeira e na Segunda Guerra Mundial nunca deveriam ocorrer novamente. O Japão em especial ficou traumatizado e profundamente marcado com os efeitos das duas bombas atômicas lançadas em Hiroshima e Nagasaki. A subsequente ocupação do Japão pelas forças aliadas no período Pós-Segunda Guerra Mundial, iniciou o processo de desmilitarização e democratização do país. Nesse período, os juristas japoneses tentavam entender o status do Japão no direito internacional, dada a ocupação das forças aliadas.

Desde o final da Primeira Guerra Mundial, o estudo da ciência direito internacional no Japão já demonstrava a tendência de se tornar mais crítico e analítico. No período Pós-Guerra, o estudo da disciplina sofreu grandes mudanças seja nos manuais da matéria ou estudo nas universidades, passou a ser orientado pela influência internacional com abordagem pacifista, ou seja, deixou de ser estatalista, oligárquico patriarcal e ortodoxo.

Estudiosos da ciência do direito internacional, como Yokota, Taoka e Tabata, continuaram suas pesquisas com maior liberdade e sob novas influências. Yokota reescreveu seu manual de direito internacional, publicado em 1948. Nesse livro, sua posição positivista jurídica ficou mais clara. Taoka e Tabata continuaram defendendo o método histórico como forma de entender as normas internacionais e suas origens.

com o potencial de empreender a guerra. A Carta Magna Japonesa é mero reflexo da tendência da comunidade internacional e do direito internacional moderno em renunciar o uso da força como meio legítimo para resolução de controvérsias, tal renúncia ocorreu, dois anos antes, na Carta das Nações Unidas de 1945. Outra mudança importante trazida pela Constituição para a nova estrutura do estado japonês foi a substituição da soberania do imperador, pela soberania popular. Isso significou a concretização de um processo democrático no país, o que implicou em maior liberdade para o povo e para os próprios juristas no Japão. Antes e durante a Segunda Guerra Mundial, a academia jurídica não gozava da liberdade de expressão que ela adquiriu, consequentemente ela passou a ter mais segurança para criticar o estado e suas instituições, sem medo da prisão ou perseguição social pelas críticas formuladas as políticas públicas (ONUMA, 1990). 
Considerando o contexto político e jurídico que o Japão vivia no período pós-guerra, as principais questões que chamavam a atenção dos internacionalistas eram: primeiro a ocupação das forças aliadas; segundo os crimes de guerra; terceiro, as questões associadas à paz e à segurança; e, quarto, questões territoriais (ONUMA, 1990).

A ocupação aliada durou quase sete anos no Japão e o tratado de paz foi oficialmente assinado somente em 1951. Esse extenso contato estrangeiro estimulou os juristas japoneses a estudarem questões associadas a acordos internacionais sobre a ocupação estrangeira e a implementação de diretivas do Comandante Supremo das Forças Aliadas (ONUMA, 1990).

Os crimes de guerra foram estudados dadas as atrocidades, torturas e outros atos desumanos, cometidos pelas forças armadas e a polícia no Japão e revelados pelo Tribunal de Crimes de Guerra de Tóquio. Yokota $(1960 ; 1973)$ defendia a legalidade do tribunal e afirmava que o julgamento e responsabilidade penal dos indivíduos que cometeram crimes de guerra e deram início a guerra de agressão, era uma consequência lógica da ilegalidade do uso da força. Outros juristas defendiam a ilegalidade do tribunal sob a alegação de violação do princípio nulum poenum sine lege, não há crime sem lei anterior que o defina. Ou seja, o tribunal não tinha legitimidade para julgar crimes vinculados à violação da paz e crimes contra a humanidade.

Questões associadas à paz e à segurança internacionais foram o principal objeto de estudo da ciência do direito internacional, de 1945 ao início dos anos 1960, tendo Yokota como seu principal estudioso. Segundo Onuma (1990), a metodologia monista de Yokota dava embasamento teórico para defender o papel que a Organização das Nações Unidas (ONU) passou a desempenhar, especialmente no que tange a segurança coletiva e a ilegalidade do uso da força. Em contrapartida, Taoka era cético quanto ao real papel desempenhado pela ONU, se esse papel não se desenvolvesse conjuntamente com a jurisdição compulsória da Corte Internacional de Justiça.

A questão da segurança internacional era analisada não somente sob seu ponto de vista teórico, mas também concreto, com a pergunta sobre a segurança no país e a constitucionalidade das forças de legítima defesa, estabelecidas pelo Tratado de Segurança entre Japão e Estados Unidos. 
Segundo entendimento da Suprema Corte Japonesa, a renúncia da guerra no $\operatorname{artigo} 9^{\circ}$ da Constituição e a proibição da manutenção do potencial de guerra não implicam em negar ao Japão seu direito inerente, como estado soberano, de se defender e repelir a ameaça estrangeira. Yokota (1960) concorda com a Suprema Corte Japonesa e completa o posicionamento jurisprudencial afirmando que o Japão renunciou ao direito de entrar em guerra, mas não o seu direito de legítima defesa.

No que tange às questões territoriais, com o fim da Segunda Guerra Mundial, alguns dos territórios que pertenciam ao Japão foram separados do país pela Declaração de Postdam de 1945. A doutrina japonesa discutia a legitimidade da anexação de facto das Ilhas Curilas ao território da União Soviética e a administração de Okinawa pelos Estados Unidos (ONUMA, 1990). Em 1965, iniciaram-se as negociações entre Estados Unidos e Japão para o retorno de Okinawa (Ilhas Ryukyu) sob forte demanda popular, no entanto, somente em 1971 a ilha foi devolvida, com um acordo entre Estado Unidos e Japão. A região tinha uma importância militar estratégica para os Estados Unidos na Ásia e ao mesmo tempo Okinawa era de facto território japonês. Com a adoção dos três princípios da não proliferação de armas nucleares pelo Japão, acordou-se que os Estados Unidos poderiam manter sua base militar na ilha, desde que sem o uso ou armazenamento de armas nucleares no Japão (ISHIMOTO; HIROBE, 1987). Até o presente momento, o Japão ainda disputa o domínio das ilhas mais ao sul de Curilas com a Rússia, reivindicando o domínio sobre as ilhas de Iturup e Kunashir, bem como as ilhas de Shikotan e Habomai.

\section{Conclusão}

Com a abertura do Japão para o ocidente, os japoneses se viram obrigados a estudar o direito internacional e adotaram uma postura pragmática. Buscaram respostas sobre as melhores práticas para a diplomacia que começava a se desenvolver. Perceberam que a abertura para o ocidente era inevitável e começaram a buscar a entender a racionalidade ocidental para estreitar laços políticos e consolidar sua condição de nação. 
O governo Meiji realizou mudanças profundas na estrutura da própria sociedade japonesa: modernizou o Japão e introduziu valores ocidentais no país. $\mathrm{O}$ estudo da ciência do direito internacional foi realizado de forma entusiasmada. Rapidamente o governo percebeu que seria essencial o conhecimento da disciplina para negociar mudanças nos diversos tratados assinados desde a Era Tokugawa. Além disso, somente por meio da demonstração da capacidade do Japão em seguir o direito internacional, poderia ser reconhecido pelo ocidente como "nação civilizada" e foi com a condução das hostilidades nas guerras Sino-Japonesa e Russo-Japonesa que o governo Meiji conseguiu tal reconhecimento.

O estudo do direito internacional como disciplina jurídica nesse período era estatalista, descritivo, passivo e eurocêntrico. Estatalista, pois, tinha como cerne as necessidades do estado; descritivo, uma vez que os juristas japoneses se preocupavam em descrever precisamente as teorias e normas europeias. Era passivo e eurocêntrico ao aceitar as teorias europeias sem questionamento, isso inicialmente se justificava por não estarem os juristas japoneses preparados para um estudo crítico e analítico do direito das gentes. Com a consolidação da posição do Japão como grande potência e seu deslocamento para o eixo europeu, passou a insistir em uma concepção asiática do direito internacional, como forma de influenciar diretamente a construção da disciplina.

A partir da Era Taisho houve um progresso na teoria geral da ciência do direito internacional. O principal pensador japonês da época foi Sakutaro Tachi que, com um posicionamento baseado no positivismo jurídico e influenciado pelas ideias de Oppenheim e Hall, contribuiu profundamente com a análise lógica das normas de direito internacional e casos concretos. As teorias elaboradas por Tachi foram utilizadas para justificar e defender as ações do Japão na Manchúria, sob a alegação da legítima defesa, com base na teoria Monroe.

No início da Era Showa, o direito internacional se consolidou como disciplina jurídica no Japão. O estudo passou a ser sistematizado, lógico e analítico, com profunda influência da teoria pura do direito de Kelsen, introduzida por Kisaburo Yokota. Outras importantes contribuições foram de Ryoichi Taoka e de Shigejiro Tabata, com a introdução e desenvolvi- 
mento do método histórico, buscando ir além da mera análise dos textos jurídicos e sim nos seus antecedentes sociológicos.

O período Pós-Segunda Guerra Mundial presenciou a mudança radical dos valores universais apregoados no direito internacional. A guerra passou a ser um meio ilegal de resolução de controvérsias e o Japão foi profundamente influenciado pela abordagem orientada na paz da comunidade internacional no pós-guerra. Com a ocupação das forças aliadas e a democratização do país, o estudo da ciência do direito internacional no Japão passou a ser influenciado pelas tendências internacionais e não mais pelo que o estado necessitava. Apesar de tudo, os estudiosos da matéria continuaram a ser profundamente influenciados pela academia europeia extraindo dali suas principais metodologias de estudo da ciência do direito internacional.

\section{Referências}

AKASHI, Kinji. Sakutaro Tachi: a blend of scholarship and practitionership and its fate in Japan. Japanese Yearbook of International Law, International Law Association of Japan, v. 56, p. 122-143, 2013.

ARIGA, Nagao. La guerre russo-japonaise au point de vue continental et le droit international d'après les documents officiels du Grand État-major japonais. Paris: A. Pedone, 1908.

ARIGA, Nagao. La guerre sino-japonaise au point vue du droit international. Paris: A. Pedone, 1896.

BLAKEMORE, Thomas L. Post-war developments in Japanese law. Wisconsin Law Review, [S.l.], v. 1, p. 632-653, July, 1947.

ISHIMOTO, Yasuo; HIROBE, Kazuya. Development of post-war japanese studies in public international law. The Japanese Annual of International Law, [S.l.], n. 30, p. 89-129, 1987. 
ISHIMOTO, Yasuo; HIROBE, Kazuya. Development of post-war japanese studies in public international law. The Japanese Annual of International Law, [S.l.], n. 31, p. 94-137, 1988.

ITO, Fujio. ONe hundred years of international law studies in Japan. The Japanese Annual of International Law, [S.l.], n. 19, p. 19-34, 1969.

KURIYAMA, Shigeru. Historical aspects of the process of international law in Japan. The Japanese Annual of International Law, [S.l.], n. 1, p.1-5, 1957.

LAM, Hok-chung. Learning the new, envisioning the new world: Meiji Japan's reading of Henry Wheaton. Japanese Yearbook of International Law, International Law Association of Japan, v. 56, 2013, p. 4-36, 2013.

LEAGUE OF NATIONS. Official Journal. C.166.M.97-1939.VII. p. 345-355, July-August, 1939.

MATSUI, Yoshiro. The social Science of international law: its evolution in Japan. The Japanese Annual of International Law, [S.l.], n. 45, p. $1-33,2002$.

OBATA, Kaoru. Historical Functions of Monism with Primacy of International Law: a view based on the Japanese experience during the early period of Allied Occupation. The Japanese Annual of International Law, [S.l.], n. 49, p. 1-35, 2006.

ONUMA, Yasuaki. Japanese international law in the prewar period perspectives on the teaching and research of international law in Prewar Japan. The Japanese Annual of International Law, [S.l.], n. 23, p. 23 47, 1986.

ONUMA, Yasuaki. Japanase international law in the postwar period perspectives on the teaching and research of international law in postwar Japan. The Japanese Annual of International Law, [S.l.], n. 25, p. 2553, 1990 .

ONUMA, Yasuaki. Takano Yuichi: personification of a liberal mind and solid scholarship. Japanese Yearbook of International Law, [S.l.], v. 53, p. 389-409, 2010. 
OPPENHEIM, L. International Law: a treatise, Peace. New York: Longmans, Green and Co., 1905. v. I.

OTSUKA, Hirohiko. Japan's early encounter with the concept of the "law of nation". The Japanese Annual of International Law, [S.l.], n. 35, p. 35-65, 1969.

PALACIOS, Héctor. Los primeiros contatos entre el Japón y los espanholes: 1543-1612. Análisis, [S.l.], v. 11, n. 31, abril, p. 35-57, 2008. PINKERT, Marvin; POTTER, Lee Ann. A letter from President Fillmore plays a key role in overcoming Japan's closed contry's policy. Social Education, National Council for Social Studies, [S.l.], v. 68, n. 2, p. 134-141, 2004. Disponível em: <http://www.socialstudies.org/ publications/socialeducation/march2004/letter-from-president-millardfillmore-to-the-emperor-of-japan>. Acesso em: 19 fev. 2017.

SHINOHARA, Hatsue. An Intellectual foundation for the road to Pearl Harbor: Quincy Wright and Tachi Sakutaro. Keisen Jogakuen College bulletin, [S.l.], n. 8, p.165-190, 1996.

TABATA, Shigejiro. Kokka Byodo Kannen no Tenkan: a transformação da concepção de igualdade dos Estados. Kyoto: Akitaya, 1946. 344 p.

TACHI, Sakutaro. Heiji Kokusaiho Ron. Tokyo: Nihon Hyoron Sha, 1930.

TACHI, Sakutaro. Senji Kokusaiho Ron. Tokyo: Nihon Hyoron Sha, 1931.

TACHI, Sakutaro. Contemporay Japan: a review of east asiatic affairs. E-Asia, University of Oregon, v. XII, n. 4, April, p. 417-425, 1943.

TACHI, Sakutaro. La porte ouverte en Chine et em Manchourie. Revue de Droit International et de Legislation Comparée, [S.l.], $3 \mathrm{~d}$ ser., p. 585-623, 1934.

TAKAHASHI, Sakue. The application of international law during the Chino-Japanese War. The Law Quarterly Review, [S.l.], n. LVI, p. 405415, 1898. 
TAKAHASHI, Sakue. Cases on International Law during the ChinoJapanese War. Cambridge: Cambridge, Eng., The University Press, 1899.

TAKAHASHI, Sakue. International Law applied to the RussoJapanese War with the Decisions of The Japanese Prize Court. New York: Banks Law Pub. Co., 1908.

TAKANO, Yuichi. Post-war studies in Public International Law in Japan. The Japanese Annual of International Law, [S.l.], n. 79, p. 79-94, 1962.

TAOKA, Ryoichi. Kushu to Kokusai ho: ataques aéreos e o Direito Internacional. Tokyo: Ganshodo Shoten, 1937.

TAOKA, Ryoichi. Kokusei Hogaku Taiko: linhas gerais do Estudo do Direito Internacional. Tokyo: Ganshodo Shoten, 1946. v. 1

TAOKA, Ryoichi. Inin Tochi no Honshitsu: a essência do sistema mandatório da Liga das Nações. Tokyo: Yuhikaku, 1941.

TAOKA, Ryoichi. Senso Ho no Kihon Mondai: problemas essenciais do Direito da Guerra. Tokyo: Iwanami Shoten, 1944.

TORIMOTO, Ikuko. Okina Kyuin and the politics of early japanese immigration to the United States: 1868-1924. Jefferson, North Carolina: Mcfarland \& Company Inc. Publishers, 2017.

UNITED NATIONS. CHINESE DELEGATION TO SECRETARY GENERAL. Sino-japanese conflict. League of Nations Official Journal, [S.l.], n. 345, July-August, 1939.

YAMAGUCHI, Susumu. Civilization and International Law in Japan during the Meiji Era (1868-1912). Hitotsubashi Journal of Law and Politics, [S.l.], n. 24, p.1-25, 1996.

YOKOTA, Kisaburo. Kokusai Soshiki ho no Riron: teoria das Organizações Internacionais. Hogaku Kyokai Zassi, [S.l.], XXXVII, n. 7, p. 8, 1929. 
YOKOTA, Kisaburo. Kokusai ho to kokunai ho no Ronnriteki

Kankei: a relação lógica entre o Direito Internacional e o Direito Interno. Yamada Kyoju Kanreki Shukuga Ronbun Shu. Yuhikaku, 1930.

YOKOTA, Kisaburo. Kokusai Ho Ron I: Direito Internacional. Tokyo: Yuhikaki, 1933.

YOKOTA, Kisaburo. Kokusai Ho Ron II: Direito Internacional. Tokyo: Yuhikaki, 1934.

YOKOTA, Kisaburo. Kokusai Ho no Hoteki Seishitsu: a natureza legal do Direito Internacional. Kokka Gakkai Zassi, Tokyo, v. LIII, n. 4, p. 5, 1939.

YOKOTA, Kisaburo. Kokusai Saiban no Honshitsu: a essência da Adjudicação internacional. Tokyo: Iwanami Shoten, 1941.

YOKOTA, Kisaburo. Kokusai ho Ron: Direito Internacional. Tokyo: Yuhikaku, 1946.

YOKOTA, Kisaburo. Kokusai Ho no Kiso Riron: a teoria fundamental do Direito Internacional. Tokyo: Yuhikaku, 1949.

YOKOTA, Kisaburo. Renunciation of War in the new Japanese Constitution: as interpreted by the Supreme Court of the Sunakawa Judgement. The Japanese Annual of International Law, [S.l.], n. 16, p. 16-31, 1960.

YOKOTA, Kisaburo. International Adjudication in Japan. The Japanese Annual of International Law, [S.l.], n.1, p. 1-20, 1973.

WHEATON, Henry. Elements of International Law. Philadelphia: Carey, Lea and Blanchard, 1836.

WHEATON, Henry. Elements of International Law. Boston: Little, Brown and Company, 1866.

ZACHMANN, Urs Matthias. Does Europe Include Japan? European Normativity in Japanese Attitudes towards International Law, 1854-1945. Rechtsgeschichte Legal History, Journal of the Max Planck Institute for European Legal History, [S.l.], Rg. 22, p. 228-243, 2014. 
Érika Louise Bastos Calazans é advogada e professora de direito internacional. Atualmente é pós-doutoranda em Direito Internacional Público pela Universidade Federal de Santa Catarina, com bolsa de pesquisa do Programa Nacional de PósDoutorado da CAPES (PNDP/CAPES), Ph.D em Direito Internacional pela Universidade de Kobe (Japão), com bolsa de pesquisa "Monbukagakusho" do governo japonês e mestre em Direito Internacional e Comunitário pela Pontifícia Universidade Católica de Minas Gerais.

E-mail: erikacalazans@gmail.com.

Endereço profissional: Universidade Federal de Santa Catarina - Campus Universitário, Trindade - Florianópolis - SC - Brasil. CEP: 88040-900. 